\title{
Vasoconstriction Potency Induced by Aminoamide Local Anesthetics Correlates with Lipid Solubility
}

\author{
Hui-Jin Sung, ${ }^{1}$ Seong-Ho Ok, ${ }^{2}$ Jin-Young Sohn, ${ }^{3}$ Yong Hyeok Son, ${ }^{3}$ Jun Kyu Kim, ${ }^{3}$ \\ Soo Hee Lee, ${ }^{1}$ Jeong Yeol Han, ${ }^{1}$ Dong Hoon Lim, ${ }^{4}$ Il-Woo Shin, ${ }^{2}$ Heon-Keun Lee, ${ }^{2}$ \\ Young-Kyun Chung, ${ }^{2}$ Mun-Jeoung Choi, ${ }^{5}$ and Ju-Tae Sohn', 2,6
}

\author{
${ }^{1}$ Department of Anesthesiology and Pain Medicine, Gyeongsang National University Hospital, Jinju 660-702, Republic of Korea \\ ${ }^{2}$ Department of Anesthesiology and Pain Medicine, Gyeongsang National University School of Medicine, \\ Jinju 660-772, Republic of Korea \\ ${ }^{3}$ Division of Chemistry, Gyeongnam Sciences High School, Jinju 660-851, Republic of Korea \\ ${ }^{4}$ Department of Information Statistics and RINS, Gyeongsang National University, Jinju 660-701, Republic of Korea \\ ${ }^{5}$ Department of Oral and Maxillofacial Surgery, Gyeongsang National University Hospital, Jinju 660-702, Republic of Korea \\ ${ }^{6}$ Institute of Health Sciences, Gyeongsang National University School of Medicine, Jinju 660-772, Republic of Korea
}

Correspondence should be addressed to Ju-Tae Sohn, jtsohn@nongae.gsnu.ac.kr

Received 25 February 2012; Accepted 18 April 2012

Academic Editor: Dobromir Dobrev

Copyright (C) 2012 Hui-Jin Sung et al. This is an open access article distributed under the Creative Commons Attribution License, which permits unrestricted use, distribution, and reproduction in any medium, provided the original work is properly cited.

\begin{abstract}
Aminoamide local anesthetics induce vasoconstriction in vivo and in vitro. The goals of this in vitro study were to investigate the potency of local anesthetic-induced vasoconstriction and to identify the physicochemical property (octanol/buffer partition coefficient, pKa, molecular weight, or potency) of local anesthetics that determines their potency in inducing isolated rat aortic ring contraction. Cumulative concentration-response curves to local anesthetics (levobupivacaine, ropivacaine, lidocaine, and mepivacaine) were obtained from isolated rat aorta. Regression analyses were performed to determine the relationship between the reported physicochemical properties of local anesthetics and the local anesthetic concentration that produced $50 \%\left(\mathrm{ED}_{50}\right)$ of the local anesthetic-induced maximum vasoconstriction. We determined the order of potency $\left(\mathrm{ED}_{50}\right)$ of vasoconstriction among local anesthetics to be levobupivacaine $>$ ropivacaine $>$ lidocaine $>$ mepivacaine. The relative importance of the independent variables that affect the vasoconstriction potency is octanol/buffer partition coefficient $>$ potency $>\mathrm{pKa}>$ molecular weight. The $\mathrm{ED}_{50}$ in endothelium-denuded aorta negatively correlated with the octanol/buffer partition coefficient of local anesthetics $\left(r^{2}=0.9563\right.$; $P<0.001)$. The potency of the vasoconstriction in the endothelium-denuded aorta induced by local anesthetics is determined primarily by lipid solubility and, in part, by other physicochemical properties including potency and pKa.
\end{abstract}

\section{Introduction}

Aminoamide local anesthetics induce vasoconstriction at low doses and vasodilation at high doses [1]. Levobupivacaine, ropivacaine, and mepivacaine are aminoamide local anesthetics that belong to the $n$-alkyl-substituted pipecholyl xylidine family [2]. Addition of carbon to the basic structure of the $n$-alkyl-substituted pipecholyl xylidine increases lipid solubility and potency $[2,3]$. In addition, the membrane disordering efficiency of local anesthetics corresponds to their potency [4].
Levobupivacaine, ropivacaine, mepivacaine, and lidocaine produce vasoconstriction both in vivo and in vitro [1, 5-12]. Levobupivacaine and ropivacaine are long-acting aminoamide local anesthetics, whereas mepivacaine and lidocaine have an intermediate duration [13]. Depending on the vascularity of the injection site, vasoconstriction induced by local anesthetic and the addition of epinephrine may contribute to decreased absorption of local anesthetics into systemic circulation [14]. This leads to prolonged nerve exposure to local anesthetics and reduced plasma levels, in addition to the potency of intrinsic vasoconstriction being 
partially associated with duration of anesthesia produced by the local anesthetic $[3,14]$. However, to our knowledge, the physicochemical property of local anesthetics that is primarily responsible for determining the local anestheticinduced vasoconstriction potency has not yet been identified. Therefore, the aims of this in vitro study were to investigate the potency of local anesthetic-induced vasoconstriction and to determine which physicochemical property is principally involved in determining this potency in isolated rat aortic rings.

\section{Materials and Methods}

All experimental procedures and protocols involving animals were performed in accordance with the Institutional Animal Care and Use Committee at Gyeongsang National University.

\subsection{Preparation of Aortic Rings for Tension Measurement.} Male Sprague Dawley rats weighing 250-300 g were anesthetized by intraperitoneal administration of pentobarbital sodium $(50 \mathrm{mg} / \mathrm{kg})$. The descending thoracic aorta was dissected, and surrounding connective tissues and fat were removed in a Krebs solution bath $(118 \mathrm{mM} \mathrm{NaCl}, 4.7 \mathrm{mM} \mathrm{KCl}$, $1.2 \mathrm{mM} \mathrm{MgSO} 4,1.2 \mathrm{mM} \mathrm{KH}_{2} \mathrm{PO}_{4}, 2.4 \mathrm{mM} \mathrm{CaCl}_{2}, 25 \mathrm{mM}$ $\mathrm{NaHCO}_{3}$, and $11 \mathrm{mM}$ glucose). The aorta was cut into $2.5 \mathrm{~mm}$ rings, suspended on Grass isometric transducers (FT-03, Grass Technologies, West Warwick, RI, USA) under $3.0 \mathrm{~g}$ resting tension in a $10 \mathrm{~mL}$ Krebs bath at $37^{\circ} \mathrm{C}$, and aerated continuously with $95 \% \mathrm{O}_{2}$ and $5 \% \mathrm{CO}_{2}$ to maintain the $\mathrm{pH}$ within a range of 7.35 to 7.45 . The rings were equilibrated for 90 min with the bathing solution changed every $30 \mathrm{~min}$. The endothelium was removed by inserting a 25 -gauge needle tip into the lumen of the rings and gently rubbing the ring for a few seconds. Once the $10^{-8} \mathrm{M}$ phenylephrine-induced contraction stabilized, endothelium removal was confirmed by observation of complete absence of relaxation induced by acetylcholine $\left(10^{-5} \mathrm{M}\right)$. Once phenylephrine $\left(10^{-7} \mathrm{M}\right)$-induced contraction had stabilized, endothelial integrity was confirmed by observation of greater than $75 \%$ relaxation upon addition of $10^{-5} \mathrm{M}$ acetylcholine. The contractile response induced by isotonic $60 \mathrm{mM}$ $\mathrm{KCl}$ was measured for all aortic rings and used as a reference value $(100 \%)$. After washing the $\mathrm{KCl}$ from the organ bath and the return of isometric tension to the baseline resting tension, cumulative concentration-response curves to local anesthetics in the endothelium-denuded aorta were obtained. The following concentrations were used for endothelium-denuded aorta: levobupivacaine: $10^{-6}$ to $3 \times$ $10^{-4} \mathrm{M}$; ropivacaine: $10^{-6}$ to $10^{-3} \mathrm{M}$; lidocaine: $10^{-6}$ to $3 \times$ $10^{-3} \mathrm{M}$; mepivacaine: $10^{-5}$ to $10^{-2} \mathrm{M}$. For endotheliumintact aorta, the concentrations were as follows: levobupivacaine: $10^{-6}$ to $3 \times 10^{-4} \mathrm{M}$; ropivacaine: $10^{-6}$ to $10^{-3} \mathrm{M}$; lidocaine: $10^{-6}$ to $10^{-2} \mathrm{M}$; mepivacaine: $10^{-5}$ to $10^{-2} \mathrm{M}$. Subsequent doses were added after the previous dose elicited a sustained and stable contraction for $5 \mathrm{~min}$. Each ring was used for one concentration-response curve. As endothelial nitric oxide attenuates the vasoconstriction induced by local anesthetics, the endothelium-denuded aortic rings were pretreated with the nitric oxide synthase inhibitor $\mathrm{N}^{W}$-nitro$\mathrm{L}$-arginine methyl ester (L-NAME, $10^{-4} \mathrm{M}$ ) to prevent release of endogenous nitric oxide from any residual endothelium before the addition of local anesthetics to the organ bath $[6,8,15]$.

2.2. Materials. All drugs used were of the highest purity available commercially. Acetylcholine, phenylephrine, and LNAME were obtained from Sigma Chemical Co. (St. Louis, MO, USA). Ropivacaine and levobupivacaine were kind gifts of AstraZeneca Korea (Seoul, Korea) and Abbott Korea (Seoul, Korea), respectively. Mepivacaine was donated by Hana Pharmaceutical Co., Ltd. (Gyeonggi-do, Korea). Lidocaine was purchased from Daihan Pharmaceutical Co., Ltd. (Seoul, Korea).

2.3. Data Analyses. Data are expressed as mean \pm standard deviation. Contractile responses to local anesthetics are expressed as a percentage of the respective maximum contraction elicited by isotonic $60 \mathrm{mM} \mathrm{KCl}$. The logarithm of the drug concentration $\left(\mathrm{ED}_{50}\right)$ eliciting $50 \%$ of the maximum contractile response was calculated using nonlinear regression analysis by fitting the concentration-response relation to a sigmoidal curve using commercially available software (Prism version 5.0; GraphPad Software, San Diego, CA, USA). $N$ indicates the number of rats from which descending thoracic aortic rings were derived. Responses to each concentration of local anesthetic were compared using repeated measures analysis of variance followed by Bonferroni posttest (Prism version 5.0; GraphPad Software). Statistical analyses for comparisons of $\mathrm{ED}_{50}$ of local anesthetics were performed using a one-way analysis of variance followed by a Bonferroni multiple comparison test. As the independent variables were highly correlated with each other (a situation called multicollinearity), a traditional regression analysis is not suitable. As an alternative, a ridge regression analysis for solving multicollinearity was performed to determine the relationship between the $\mathrm{ED}_{50}$ of local anesthetic-induced vasoconstriction in endothelium-denuded aorta and the reported physicochemical properties of local anesthetics (Table 1) using SAS statistical software for Windows, version 9.1 (SAS Institute Inc., Cary, NC, USA) [3, 16-21]. Standardized coefficients are estimates resulting from an analysis carried out on variables that have been standardized so that their variances are 1 [22]. Standardized regression coefficients (SRCs) were used to determine which independent variables among octanol/ buffer partition coefficient, molecular weight, pKa, and potency have a greater effect on dependent variables like $\mathrm{ED}_{50}$ in the multiple regression analysis when the variables are measured in different units of measurement (e.g., $\mathrm{g} / \mathrm{mol}, \log$ [octanol/buffer partition coefficient], $-\log \mathrm{Ka}$, or potency) [22]. In addition, in isolated aortas, linear regression analysis was performed to determine whether a correlation exists between the $\mathrm{ED}_{50}$ of local anesthetic-induced maximal vasoconstriction in the endothelium-denuded aorta, the local anesthetic concentration that produced the maximal contraction in the endothelium-intact aorta, and the reported octanol/buffer partition coefficient of local 
TABLE 1: Molecular weight, lipid solubility, pKa, and potency of local anesthetics [3, 16-20].

\begin{tabular}{lcccc}
\hline & $\begin{array}{c}\text { MW (g/mol) } \\
\text { (base form) }\end{array}$ & $\begin{array}{c}\text { Lipid solubility (log } \\
\text { [octanol/buffer partition } \\
\text { coefficient]) at pH 7.4 }\end{array}$ & $\begin{array}{c}\text { pKa }(-\log \text { Ka }) \\
\text { at } 36^{\circ} \mathrm{C}\end{array}$ & Potency* $^{*}$ \\
\hline Levobupivacaine & 288 & 2.539 & 8.1 & 8 \\
Ropivacaine & 274 & 2.060 & 8.1 & 6 \\
Lidocaine & 234 & 1.633 & 7.8 & 2 \\
Mepivacaine & 246 & 1.322 & 7.7 & 1.5 \\
\hline
\end{tabular}

MW: molecular weight.

Ka: dissociation constant.

* Data derived from $C$ fibers of isolated rabbit vagus and sciatic nerve $[3,17,20]$.

anesthetics (Table 1 ). $P$ values $<0.05$ were considered significant.

\section{Results}

In endothelium-denuded and -intact aorta, levobupivacaine, ropivacaine, lidocaine, and mepivacaine produced vasoconstriction at low doses and vasodilation at high doses (Figure 1). We determined the order of vasoconstriction potency $\left(\mathrm{ED}_{50}\right)$ among local anesthetics to be levobupivacaine $>$ ropivacaine $>$ lidocaine $>$ mepivacaine (Table 2 ). The local anesthetic concentration that leads to maximal contraction in endothelium-intact aorta was $10^{-4}$ for levobupivacaine, $3 \times 10^{-4}$ for ropivacaine, $3 \times 10^{-3}$ for lidocaine, and $3 \times 10^{-3} \mathrm{M}$ for mepivacaine (Figure $1(\mathrm{~b})$ ). The fitted ridge reg-ression equation for the relationship between the log $\mathrm{ED}_{50}$ of endothelium-denuded aorta and the reported physiochemical properties (logarithm of octanol/buffer partition coefficient $[\log P]$, molecular weight $[\mathrm{g} / \mathrm{mol}], \mathrm{pKa}[-\log \mathrm{Ka}]$, and potency; Table 1) is $\log \mathrm{ED}_{50}=2.1691-0.6244 \times \mathrm{pKa}-$ $0.5534 \times \log P-0.0480 \times$ potency $+0.0004 \times$ molecular weight $\left(r^{2}=0.923\right)[3,16-21]$. Furthermore, the ridge regression analysis using SRCs showed that the octanol/buffer partition coefficient was the main factor that determined the local anesthetic-induced vasoconstriction potency in endothelium-denuded aorta (Table 3). This is because the absolute value of SRC $(-0.4701)$ of octanol/buffer partition coefficient was the highest among the independent variables representing the physicochemical properties of local anesthetics. Table 3 shows that the order of relative importance of the physicochemical properties affecting the local anestheticinduced vasoconstriction potency was octanol/buffer partition coefficient (SRC: -0.4701$)>$ potency $($ SRC: -0.2428$)>$ pKa (SRC: -0.2068$)>$ molecular weight (SRC: +0.0169 ). The logarithm of $\mathrm{ED}_{50}$ in endothelium-denuded aorta negatively correlated with the logarithm of octanol/buffer partition coefficient $\left(\log \mathrm{ED}_{50}=-1.750-1.151 \times \log P ; r^{2}=\right.$ $0.9563 ; P<0.001$; Figure 2$)$. In addition, the local anesthetic concentration that produced maximal vasoconstriction in endothelium-intact aorta negatively correlated with the octanol/buffer partition coefficient of local anesthetics (log [local anesthetic concentration producing maximal vasoconstriction] $\left.=-0.461-1.407 \times \log P ; r^{2}=0.9283 ; P<0.001\right)$.

\section{Discussion}

This is the first paper to suggest that the lipid solubility of local anesthetics is principally involved in determining the potency of local anesthetic-induced vasoconstriction at low doses. The perturbation effect of local anesthetics on membrane and lipid solubility correlates with the potency of local anesthetics $[4,23]$. Highly lipophilic local anesthetics, such as levobupivacaine, may have significant effects on the lipid environment of cell membranes, altering the gating of ion channels including calcium channels [24]. Transient receptor potential canonical channels are thought to be involved in determining entry through sodium or calcium channels, which are modulated by cell membrane lipids and anesthetics [25]. The vasoconstriction induced by local anesthetics at low doses appears to be mainly dependent on calcium influx via voltage-operated calcium channels $[5-8,26,27]$. According to our ridge regression analyses with SRCs, the order of importance of the independent variables that affect the potency $\left(\mathrm{ED}_{50}\right)$ of vasoconstriction is octanol/buffer partition coefficient $>$ potency $>\mathrm{pKa}>$ molecular weight (Table 3) [22]. Therefore, the octanol/ buffer partition coefficient is the most important independent variable involved in determining the $\mathrm{ED}_{50}$. The decreasing order of octanol/buffer partition coefficients of local anesthetics is levobupivacaine $(2.539)>$ ropivacaine $(2.060)>$ lidocaine $(1.633)>$ mepivacaine $(1.322)$ [16]. In addition, the relative anesthetic potency of levobupivacaine, ropivacaine, lidocaine, and mepivacaine is $8,6,2$, and 1.5 , respectively, (Table 1) [3, 17, 20]. Taking into consideration the order of potency of both $\mathrm{ED}_{50}$ in endothelium-denuded aorta and the local anesthetic concentration that produces maximal vasoconstriction in endothelium-intact aorta (Figure 1 and Table 2), the order of lipid solubility and potency of local anesthetics approximately follows the order of potency of local anesthetic-induced vasoconstriction. Taken together with previous papers, our results for the potency of vasoconstriction induced by low-dose local anes-thetics via activation of calcium influx may be related to the magnitude of modulation of transient receptor potential canonical channels caused by changes in the lipid environment of cell membranes which in turn may be correlated with lipid solubility, such as the octanol/buffer partition coefficient of local anesthetics [4-8, 23-27]. In contrast to the order of potency of $\mathrm{ED}_{50}$ in endothelium-denuded aorta, the magnitude 


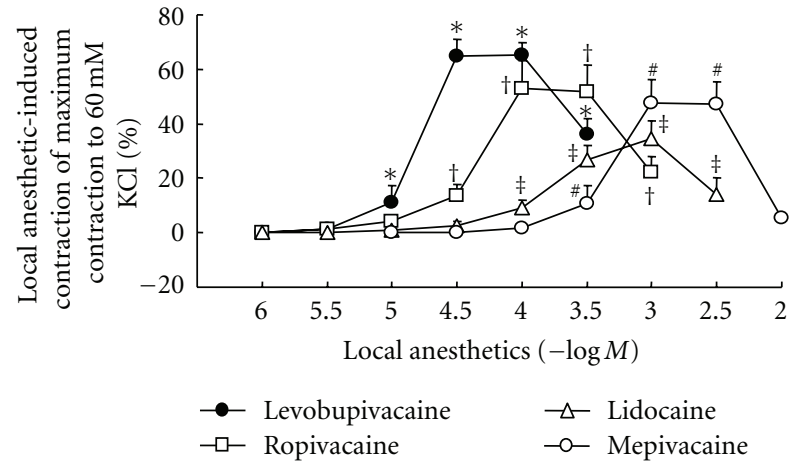

(a)

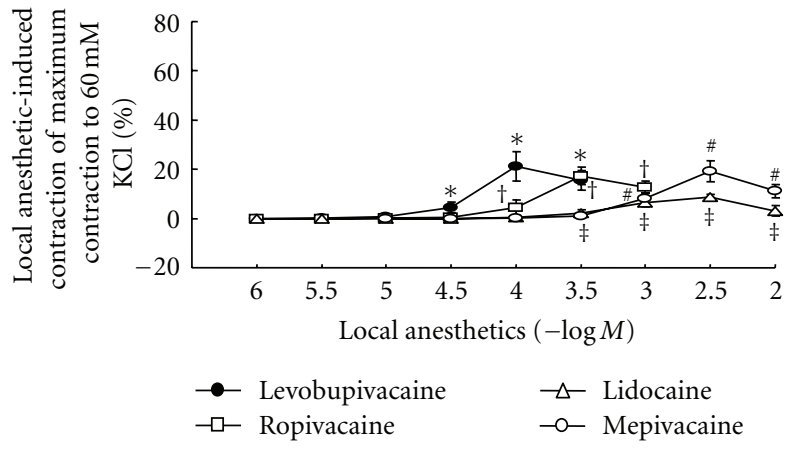

(b)

FIGURE 1: Concentration-response curves induced by levobupivacaine, ropivacaine, lidocaine, and mepivacaine in isolated endotheliumdenuded (a) and -intact (b) aorta. All values are shown as mean \pm SD and expressed as the percentage of the maximal contraction induced by $60 \mathrm{mM} \mathrm{KCl}$. N indicates the number of rats from which descending thoracic aortic rings were derived. (a) Isotonic $60 \mathrm{mM} \mathrm{KCl}$-induced contraction in endothelium-denuded aorta: $100 \%=2.94 \pm 0.66 \mathrm{~g}(n=6)$ with levobupivacaine, $100 \%=3.24 \pm 0.51 \mathrm{~g}(n=6)$ with ropivacaine, $100 \%=2.88 \pm 0.49 \mathrm{~g}(n=6)$ with lidocaine, and $100 \%=2.91 \pm 0.36 \mathrm{~g}(n=6)$ with mepivacaine. ${ }^{*} P<0.01$ versus $10^{-6} \mathrm{M}$ levobupivacaine; ${ }^{\dagger} P<0.01$ versus $10^{-6} \mathrm{M}$ ropivacaine; ${ }^{\ddagger} P<0.01$ versus $10^{-6} \mathrm{M}$ lidocaine; ${ }^{\#} P<0.01$ versus $10^{-5} \mathrm{M}$ mepivacaine. (b) Isotonic $60 \mathrm{mM} \mathrm{KCl}$ induced contraction in endothelium-intact aorta: $100 \%=2.42 \pm 0.50 \mathrm{~g}(n=6)$ with levobupivacaine, $100 \%=2.44 \pm 0.43 \mathrm{~g}(n=6)$ with ropivacaine, $100 \%=2.11 \pm 0.56 \mathrm{~g}(n=6)$ with lidocaine, and $100 \%=2.43 \pm 0.28 \mathrm{~g}(n=6)$ with mepivacaine. ${ }^{*} P<0.001$ versus $10^{-6} \mathrm{M}$ levobupivacaine; ${ }^{\dagger} P<0.01$ versus $10^{-6} \mathrm{M}$ ropivacaine; ${ }^{\ddagger} P<0.05$ versus $10^{-6} \mathrm{M}$ lidocaine; ${ }^{\#} P<0.001$ versus $10^{-5} \mathrm{M}$ mepivacaine.

TABLE 2: The concentration $\left(\mathrm{ED}_{50}\right)$ eliciting $50 \%$ of maximum contraction induced by local anesthetics in endothelium-denuded aorta.

\begin{tabular}{|c|c|c|c|}
\hline Local anesthetics & $N$ & $\log \mathrm{ED}_{50}$ & $\begin{array}{l}\text { Contraction induced } \\
\text { by } 60 \mathrm{mM} \mathrm{KCl}(\mathrm{g})\end{array}$ \\
\hline Levobupivacaine & 6 & $-4.65 \pm 0.08$ & $2.94 \pm 0.66$ \\
\hline Ropivacaine & 6 & $-4.11 \pm 0.07^{*}$ & $3.24 \pm 0.51$ \\
\hline Lidocaine & 6 & $-3.74 \pm 0.15^{*, \dagger}$ & $2.88 \pm 0.49$ \\
\hline Mepivacaine & 6 & $-3.20 \pm 0.07^{*, \dagger, \ddagger}$ & $2.91 \pm 0.36$ \\
\hline
\end{tabular}

Values are expressed as mean $\pm \mathrm{SD}$.

$N$ : number of rats.

${ }^{*} P<0.001$ versus levobupivacaine, ${ }^{\dagger} P<0.001$ versus ropivacaine, ${ }^{\ddagger} P<0.001$ versus lidocaine.

TABLE 3: Ridge regression analysis using standardized regression coefficients regarding the relationship between the dependent variable (representing the local anesthetic concentration eliciting 50\% of maximum contraction) and the independent variables (representing physicochemical properties).

\begin{tabular}{lc}
\hline Independent variables & $\begin{array}{c}\text { Standardized regression } \\
\text { coefficient }\end{array}$ \\
\hline Octanol/buffer partition coefficient $(\log$ & -0.4701 \\
[octanol/buffer partition coefficient]) & +0.0169 \\
Molecular weight (g/mol) (base form) & -0.2068 \\
$\mathrm{pKa}(-\log \mathrm{Ka})$ & -0.2428 \\
\hline
\end{tabular}

Ka: dissociation constant.

of maximal contraction induced by local anesthetics in endothelium-intact aorta was higher for mepivacaine than for lidocaine. This difference between mepivacaine and lidocaine may be due to differences in endothelial nitric oxide release induced by mepivacaine and lidocaine [27]. Further research into the potential relationship between the lipid solubility of local anesthetics and calcium influx via voltage-operated calcium channels activated by local anesthetics is needed to determine the detailed mechanism of the vasoconstriction.

Increased molecular weight caused by increasing the number of carbons on the basic molecular structure (either on the end of the structure or linkage site, including amides and esters) of local anesthetics enhances potency and lipid solubility [3]. Lipid solubility is a major determinant of the ability of local anesthetics to diffuse through cell membranes composed of lipid bilayers [18]. Therefore, the higher the octanol/buffer partition coefficient, the higher local anesthetic potency [18]. The pKa is a constant that determines the unionized form of local anesthetic which rapidly passes through cell membranes and accelerates the onset of anesthesia [18]. The disordering effect of local anesthetics on the hydrocarbon core of the membrane is correlated with the potency of local anesthetics [4]. A strong correlation exists between lipid solubility of local anesthetics and A fiber conduction blocking potency of local anesthetics [23]. As these physicochemical properties of local anesthetics are strongly correlated with each other (so called multicollinearity), 


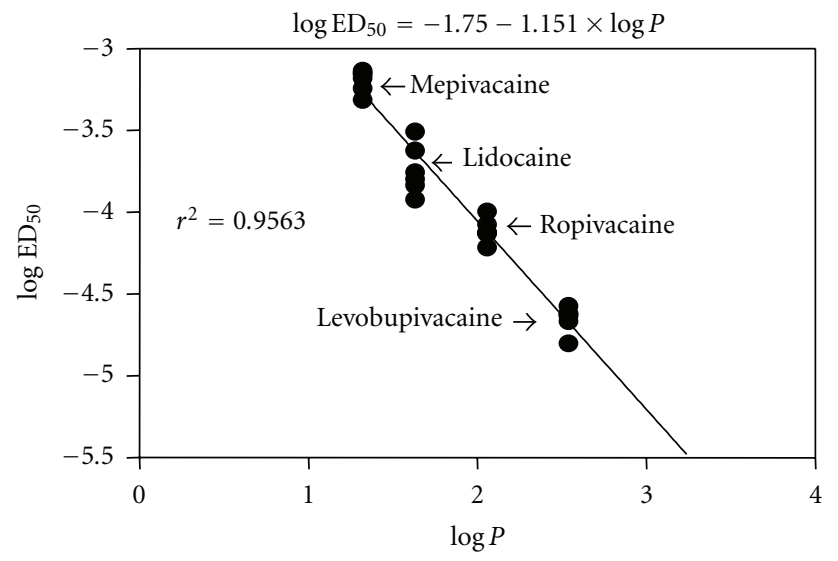

FIGURE 2: Relationship between logarithm of local anesthetic concentration producing $50 \%$ of the local anesthetic-induced maximal contraction $\left(\mathrm{ED}_{50}\right)$ in isolated endothelium-denuded aorta and logarithm of octanol/buffer partition coefficient $(\log P)$ of local anesthetics. All values are shown as mean \pm SD. Each anesthetic was tested in aortic rings from six rats.

we used ridge regression analyses to investigate relationships between the potency of local anesthetic-induced vasoconstriction and the independent variables representing the physicochemical properties of local anesthetics $[3,4,18$, 23]. Together with previous data, our results suggest that the potency of local anesthetic-induced vasoconstriction is determined primarily by lipid solubility and, in part, by other physicochemical properties, including potency and $\mathrm{pKa}[3,4$, $18,23]$.

In addition, treatment with lipid emulsion attenuates the vasoconstriction induced by levobupivacaine and ropivacaine, whereas lipid emulsion treatment does not significantly affect mepivacaine-induced vasoconstriction [5]. The magnitude of lipid emulsion-mediated attenuation of the levobupivacaine-induced vasoconstriction is higher than that of the ropivacaine-induced vasoconstriction, suggesting that the magnitude of lipid emulsion-mediated attenuation of vasoconstriction induced by local anesthetics is mainly dependent on lipid solubility [5]. These results suggest that the vasoconstriction induced by highly lipid soluble local anesthetics (e.g., levobupivacaine) is easily attenuated by lipid emulsion, because the higher the lipid solubility of local anesthetics, the greater the amount of local anesthetics dissolved into the lipid emulsion, rather than into the aortic ring cell membrane $[5,13]$. The clinical implication for the relationship between the potency of local anestheticinduced vasoconstriction and lipid solubility identified in this in vitro study must be tempered by the fact that these results were obtained in aorta, whereas blood flow to organs, including spinal cord and peripheral nerves, is controlled by changes in the diameter of small resistance arteriole. Even considering this limitation, our results suggest that the relatively high potency of vasoconstriction induced by levobupivacaine and ropivacaine may contribute to their long duration of anesthesia because of decreased systemic absorption due to strong intrinsic vasoconstriction [5-11, 13, 14]. The relatively low potency of vasoconstriction induced by lidocaine and mepivacaine may be partially associated with the intermediate duration of anesthesia induced by these drugs [12-14]. The combination of epinephrine plus levobupivacaine has no effect on prolonging the sensory block compared with levobupivacaine alone [28]. Combined pretreatment with epinephrine plus ropivacaine has no effect on the reduction of nerve blood flow compared with ropivacaine alone [29]. These previous results may be due to the strong intrinsic vasoconstriction induced by levobupivacaine or ropivacaine that we observed in this in vitro experiment $[28,29]$. The magnitude of nerve blood flow reduction induced by local anesthetics is higher with ropivacaine than with levobupivacaine [29]. The differences between our current study and the previous paper may be due to various factors, including single concentration-induced vascular response without considering the dose-dependent biphasic vascular response (vasoconstriction and vasodilation) induced by local anesthetics, experimental conditions (in vivo versus in vitro), or source (sciatic nerve blood flow versus aorta) [29]. One theory regarding the mechanism of action of intravenous lipid emulsion as a rescue therapy for the cardiovascular collapse induced by toxic doses of local anesthetics is the "lipid sink" theory that lipid emulsion provides a large lipid phase that extracts local anesthetics from serum and tissue $[5,13]$. Together with previous papers, our result as to which lipid solubility is the major factor determining the potency of local anesthetic-induced vasoconstriction may support the "lipid sink" theory as a possible mechanism responsible for lipid rescue therapy [5, 13, 30-33].

Levobupivacaine is clinically used at concentrations of $0.25 \%$ to $0.75 \%$ (equivalent to approximately $8.7 \times 10^{-3}$ to $\left.2.6 \times 10^{-2} \mathrm{M}\right)$. The maximum plasma concentration following scalp block with levobupivacaine is $5.4 \times 10^{-6} \mathrm{M}$, and the expected tissue concentration encountered in the clinical setting with $95 \%$ protein binding ranges from $0.27 \times 10^{-6} \mathrm{M}$ to $1.3 \times 10^{-3} \mathrm{M}[3,34]$. Ropivacaine is clinically used at concentrations of $0.25 \%$ to $0.75 \%$ (equivalent to approximately $9.1 \times 10^{-3}$ to $2.73 \times 10^{-2} \mathrm{M}$ ), and the expected local tissue concentration encountered in the clinical setting with $94 \%$ protein binding ranges from $5.46 \times 10^{-4} \mathrm{M}$ to $1.63 \times 10^{-3} \mathrm{M}$ [3]. Mepivacaine is clinically used at concentrations of $0.5 \%$ 
to $2 \%$ (equivalent to approximately $1.75 \times 10^{-2}$ to $7 \times$ $10^{-2} \mathrm{M}$ ), and the expected local tissue concentration encountered in the clinical setting with $77.5 \%$ protein binding ranges from $3.937 \times 10^{-3}$ to $1.575 \times 10^{-2} \mathrm{M}$ [3]. Lidocaine is clinically used at concentration of 0.5 to $4 \%$ (equivalent to approximately $2.13 \times 10^{-2}$ to $1.70 \times 10^{-1} \mathrm{M}$ ). The mean plasma concentration of lidocaine as antiarrhythmic drug is $10^{-5} \mathrm{M}$, and the expected tissue concentration encountered in the clinical setting with $64 \%$ protein binding ranges from $3.6 \times 10^{-6}$ to $6.12 \times 10^{-2} \mathrm{M}[3,35]$. However, we hypothesize that the actual local tissue concentration of local anesthetics may be lower than expected, because if locally applied, the anesthetic is diluted with interstitial fluid and absorbed into fat tissue around nerve block site. Therefore, we suggest these supposed local tissue concentrations include the range of concentrations of local anesthetics producing vasoconstriction observed in this in vitro study.

In conclusion, these results suggest that the octanol/buffer partition coefficient of local anesthetics is the primary factor in determining the potency of local anesthetic-induced vasoconstriction. We determined the order of potency of vasoconstriction induced by local anesthetics in isolated endothelium-denuded aorta to be levobupivacaine $>$ ropivacaine $>$ lidocaine $>$ mepivacaine.

\section{Conflict of Interests}

The authors declared no conflict of interests.

\section{Acknowledgment}

This research was supported by the Basic Science Research Program through the National Research Foundation of Korea (NRF) funded by the Ministry of Education, Science, and Technology (KRF-2011-0006783).

\section{References}

[1] J. B. Löfström, "The effect of local anesthetics on the peripheral vasculature," Regional Anesthesia, vol. 17, no. 1, pp. 1-11, 1992.

[2] A. Casati and M. Putzu, "Bupivacaine, levobupivacaine and ropivacaine: are they clinically different?" Best Practice and Research: Clinical Anaesthesiology, vol. 19, no. 2, pp. 247-268, 2005.

[3] J. E. Heavner, "Local anesthetics," Current Opinion in Anesthesiology, vol. 20, pp. 336-342, 2007.

[4] K. Ondrias, P. Balgavý, S. Stolc, and L. I. Horváth, "A spin label study of the perturbation effect of tertiary amine anesthetics on brain lipid liposomes and synaptosomes," Biochimica et Biophysica Acta, vol. 732, no. 3, pp. 627-635, 1983.

[5] S. H. Ok, J. T. Sohn, J. S. Baik et al., "Lipid emulsion reverses levobupivacaine-induced responses in isolated rat aortic vessels," Anesthesiology, vol. 114, no. 2, pp. 293-301, 2011.

[6] J. S. Baik, J. T. Sohn, S. H. Ok et al., "Levobupivacaine-induced contraction of isolated rat aorta is calcium dependent," Canadian Journal of Physiology and Pharmacology, vol. 89, pp. 467476, 2011.

[7] H. J. Sung, J. T. Sohn, J. Y. Park, E. M. Hwang, J. S. Baik, and K. Ogawa, "Direct effect of ropivacaine involves lipoxygenase pathway activation in rat aortic smooth muscle," Canadian Journal of Anesthesia, vol. 56, no. 4, pp. 298-306, 2009.

[8] Y. S. Choi, Y. S. Jeong, S. H. Ok et al., "The direct effect of levobupivacaine in isolated rat aorta involves lipoxygenase pathway activation and endothelial nitric oxide release," Anesthesia and Analgesia, vol. 110, no. 2, pp. 341-349, 2010.

[9] H. S. Shim, S. H. Ok, S. H. Lee, S. C. Kwon, and J. T. Sohn, "Protein kinases participate in the contraction in response to levobupivacaine in the rat aorta," European Journal of Pharmacology, vol. 677, pp. 331-337, 2012.

[10] D. J. Newton, D. Burke, F. Khan et al., "Skin blood flow changes in response to intradermal injection of bupivacaine and levobupivacaine, assessed by laser doppler imaging," Regional Anesthesia and Pain Medicine, vol. 25, no. 6, pp. 626-631, 2000.

[11] I. Cederholm, H. Evers, and J. B. Löfström, "Skin blood flow after intradermal injection of ropivacaine in various concentrations with and without epinephrine evaluated by laser doppler flowmetry," Regional Anesthesia, vol. 17, no. 6, pp. 322328, 1992.

[12] D. G. Willatts and F. Reynolds, "Comparison of the vasoactivity of amide and ester local anaesthetics: an intradermal study," British Journal of Anaesthesia, vol. 57, no. 10, pp. 1006-1011, 1985.

[13] K. L. Felice and H. M. Schumann, "Intravenous lipid emulsion for local anesthetic toxicity: a review of the literature," Journal of Medical Toxicology, vol. 4, no. 3, pp. 184-191, 2008.

[14] S. Liu, R. L. Carpenter, A. A. Chiu, T. J. McGill, and S. A. Mantell, "Epinephrine prolongs duration of subcutaneous infiltration of local anesthesia in a dose-related manner: correlation with magnitude of vasoconstriction," Regional Anesthesia, vol. 20, no. 5, pp. 378-384, 1995.

[15] Y. S. Choi, S. H. Ok, S. M. Lee et al., "Indigo carmine enhances phenylephrine-induced contractions in an isolated rat aorta," Korean Journal of Anesthesiology, vol. 61, pp. 55-62, 2011.

[16] G. R. Strichartz, V. Sanchez, G. R. Arthur, R. Chafetz, and D. Martin, "Fundamental properties of local anesthetics. II. Measured octanol: buffer partition coefficients and $\mathrm{pKa}$ values of clinically used drugs," Anesthesia and Analgesia, vol. 71, no. 2, pp. 158-170, 1990.

[17] C. B. Berde and G. R. Strichartz, "Local anesthetics," in Miller's Anesthesia, R. D. Miller, L. I. Eriksson, L. A. Fleisher, J. P. Wiener-Kronish, and W. L. Young, Eds., pp. .917-918, Churchill-Livingstone, Philadelphia, Pa, USA, 7th edition, 2010.

[18] H. A. McLure and A. P. Rubin, "Review of local anaesthetic agents," Minerva Anestesiologica, vol. 71, no. 3, pp. 59-74, 2005.

[19] S. Leone, S. Di Cianni, A. Casati, and G. Fanelli, "Pharmacology, toxicology, and clinical use of new long acting local anesthetics, ropivacaine and levobupivacaine," Acta Biomedica de l'Ateneo Parmense, vol. 79, no. 2, pp. 92-105, 2008.

[20] A. J. Gissen, B. G. Covino, and J. Gregus, "Differential sensitivities of mammalian nerve fibers to local anesthetic agents," Anesthesiology, vol. 53, no. 6, pp. 467-474, 1980.

[21] A. E. Hoerl and R. W. Kennard, "Ridge regression: biased estimation for nonorthogonal problems," Technometrics, vol. 12, pp. 55-67, 1970.

[22] L. D Schroeder, D. L Sjoquist, and P. E. Stephan, Understanding Regression Analysis: An Introductory Guide, Sage Publications, Newbury Park, Calif, USA, 2nd edition, 1986.

[23] J. A. W. Wildsmith, A. J. Gissen, J. Gregus, and B. G. Covino, "Differential nerve blocking activity of amino-ester local anaesthetics," British Journal of Anaesthesia, vol. 57, no. 6, pp. 612-620, 1985. 
[24] P. Friederich, "Basic concepts of ion channel physiology and anaesthetic drug effects," European Journal of Anaesthesiology, vol. 20, no. 5, pp. 343-353, 2003.

[25] D. J. Beech, Y. M. Bahnasi, A. M. Dedman, and E. AL-Shawaf, "TRPC channel lipid specificity and mechanisms of lipid regulation," Cell Calcium, vol. 45, no. 6, pp. 583-588, 2009.

[26] H. Noren, B. Lindblom, and B. Källfelt, "Effects of bupivacaine and calcium antagonists on human uterine arteries in pregnant and non-pregnant women," Acta Anaesthesiologica Scandinavica, vol. 35, no. 6, pp. 488-491, 1991.

[27] J. T. Sohn, S. H. Ok, and J. G. Kim, "Direct effect of mepivacaine involves endothelial nitric oxide release of isolated rat aorta. A1022," in Proceedings of the Annual Meeting of American Society of Anesthesiologists, San Diego, Calif, USA, October 2010.

[28] D. J. Kopacz, J. D. Helman, C. E. Nussbaum, J. N. K. Hsiang, P. C. Nora, and H. W. Allen, "A comparison of epidural levobupivacaine $0.5 \%$ With or without epinephrine for lumbar spine surgery," Anesthesia and Analgesia, vol. 93, no. 3, pp. 755-760, 2001.

[29] H. Bouaziz, G. Iohom, J. P. Estèbe, W. M. Campana, and R. R. Myers, "Effects of levobupivacaine and ropivacaine on rat sciatic nerve blood flow," British Journal of Anaesthesia, vol. 95, no. 5, pp. 696-700, 2005.

[30] G. L. Weinberg, R. Ripper, P. Murphy et al., "Lipid infusion accelerates removal of bupivacaine and recovery from bupivacaine toxicity in the isolated rat heart," Regional Anesthesia and Pain Medicine, vol. 31, no. 4, pp. 296-303, 2006.

[31] M. A. Rosenblatt, M. Abel, G. W. Fischer, C. J. Itzkovich, and J. B. Eisenkraft, "Successful use of a $20 \%$ lipid emulsion to resuscitate a patient after a presumed bupivacaine-related cardiac arrest," Anesthesiology, vol. 105, no. 1, pp. 217-218, 2006.

[32] R. J. Litz, M. Popp, S. N. Stehr, and T. Koch, "Successful resuscitation of a patient with ropivacaine-induced asystole after axillary plexus block using lipid infusion," Anaesthesia, vol. 61, no. 8, pp. 800-801, 2006.

[33] G. Foxall, R. McCahon, J. Lamb, J. G. Hardman, and N. M. Bedforth, "Levobupivacaine-induced seizures and cardiovascular collapse treated with Intralipid ${ }^{\circledR,}$, Anaesthesia, vol. 62, no. 5, pp. 516-518, 2007.

[34] T. G. Costello, J. R. Cormack, L. E. Mather, B. LaFerlita, M. A. Murphy, and K. Harris, "Plasma levobupivacaine concentrations following scalp block in patients undergoing awake craniotomy," British Journal of Anaesthesia, vol. 94, no. 6, pp. 848-851, 2005.

[35] N. A. M. Estes III, A. S. Manolis, D. J. Greenblatt, H. Garan, and J. N. Ruskin, "Therapeutic serum lidocaine and metabolite concentrations in patients undergoing electrophysiologic study after discontinuation of intravenous lidocaine infusion," American Heart Journal, vol. 117, no. 5, pp. 1060-1064, 1989. 


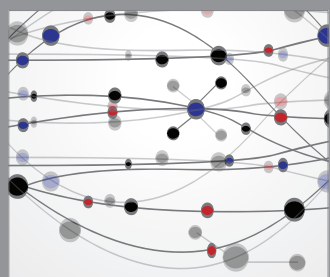

The Scientific World Journal
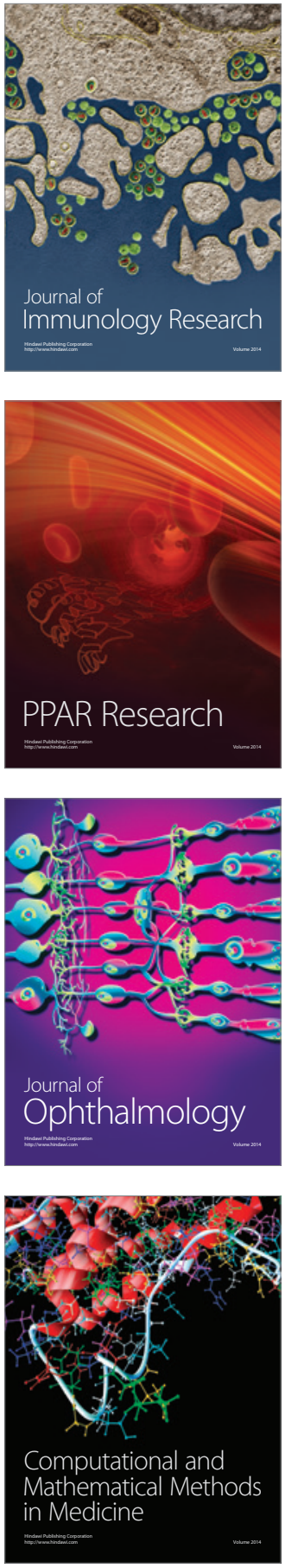

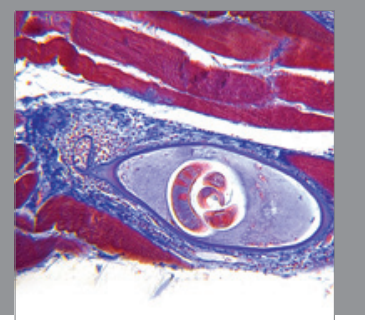

Gastroenterology

Research and Practice
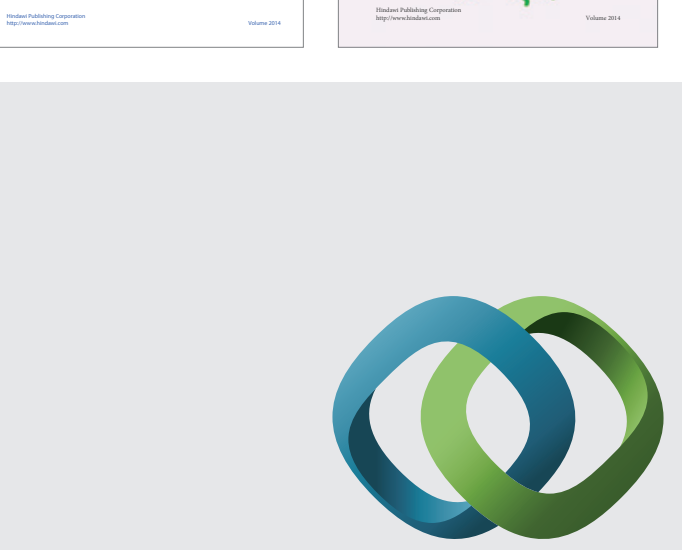

\section{Hindawi}

Submit your manuscripts at

http://www.hindawi.com
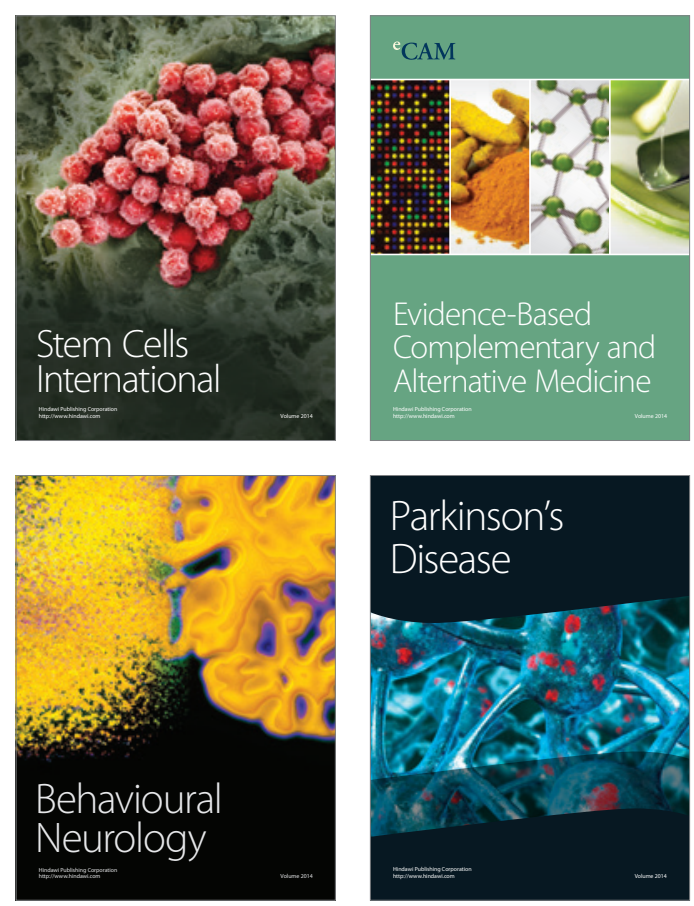

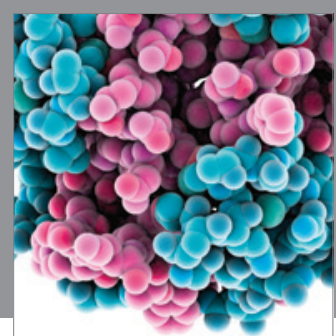

Journal of
Diabetes Research

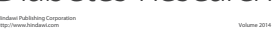

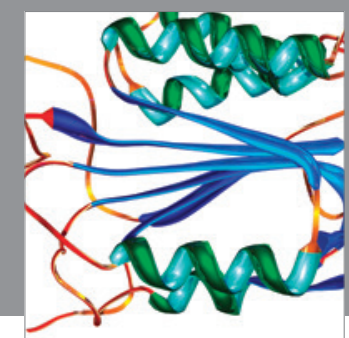

Disease Markers
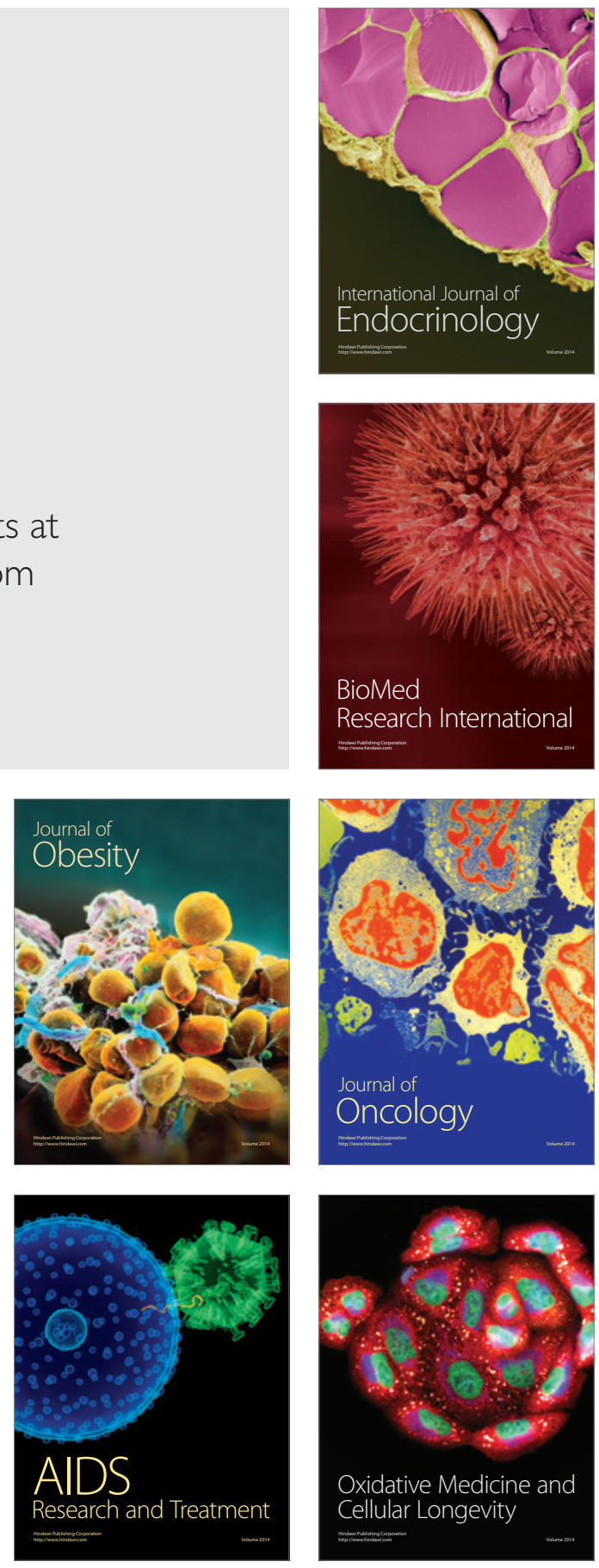